\title{
Sensing technologies for detection of non-point source pollutants in rice paddy fields
}

\author{
Yali Zhang ${ }^{1,2}$, Yuan $\mathrm{Q}^{1,2}$, Linlin Wang ${ }^{2,3}$, Kangting Yan ${ }^{1,2}$, Ruichang Jia ${ }^{1,2^{*}}$ \\ (1. College of Engineering, South China Agricultural University, Guangzhou 510642, China; \\ 2. National Center for International Collaboration Research on Precision, Agricultural Aviation Pesticides Spraying Technology, \\ Guangzhou 510642, China; \\ 3. College of Electronic Engineering, South China Agricultural University, Guangzhou 510642, China)
}

\begin{abstract}
With increased input in agriculture, the excessive use of pesticides and fertilizers has caused various pollutions in farmland. Non-point source pollution in agriculture, especially in paddy fields, has been a serious threat to the health of water environment. Therefore, the rapid detection and analysis of important pollutants in the paddy water environment is of great significance for controlling agricultural non-point source pollution and avoiding the occurrence of large-scale water pollution disasters in the future. Based on the detection method of non-point source pollutants in rice fields, this paper introduces the pollution and harm caused by eutrophication of water body, nitrate pollution of groundwater, organochlorine and organophosphorus pesticide residues. The advantages and disadvantages of the above four pollutants detection methods and their application status in rapid, on-line detection or satellite remote sensing monitoring are summarized, and future research is prospected. The detection methods of non-point source pollutants in the paddy water environment can solve the problem of detecting substances well, but they all need to be sampled back to the laboratory, and the timeliness is poor, which cannot meet the requirements of fast real-time. For some of the on-site inspection instruments, their volume and portability are currently problems to be solved. To solve the problem of online or rapid detection of non-point source pollutants in rice water environment, we need to start from the following four aspects: strengthen fast online real-time monitoring technology, develop water pollutant detection sensors, research wireless sensor network technology and combine UAV airborne remote sensing technology. In the future, strengthening the research of online real-time detection technology will provide a theoretical basis for the online, rapid and accurate determination of pollutants in rice fields and the development of related rapid detection instruments.
\end{abstract} Keywords: non-point source pollution, water environment, paddy field, remote sensing DOI: $10.33440 / j . i j p a a .20200303 .102$

Citation: Zhang Y L, Qi Y, Wang L L, Yan K T, Jia R C. Sensing technologies for detection of non-point source pollutants in rice paddy fields. Int J Precis Agric Aviat, 2020; 3(3): 1-13.

\section{Introduction}

Water resources are extremely important for human survival and development, since rivers and lakes are indispensable natural resources in the production and life of human society. With the improvement of the ability to control the point source pollution, people gradually realize the severity of non-point source pollution. In the past decade in China, most of the pollution in many plain lakes and reservoirs comes from agricultural non-point sources ${ }^{[1]}$. Among them, the harm to water environment brought by paddy fields, from which the main crop of China-rice is cultivated, cannot be underestimated. At present, the area for rice producing accounts for $1 / 3$ of the farmland in China, and its planting area has reached 30 million hectares ${ }^{[2]}$. Since the whole growth cycle of rice requires large amount of water, to irrigate and drain off water

\section{Received date: $2020-8-25 \quad$ Accepted date: $2020-9-17$}

Biographies: Yali Zhang, PhD, Associate Professor, research interests: precision application sensor technology for UAV. Email: ylzhang@scau.edu.cn; Yuan Qi, Master student, research interests: UAV remote sensing image processing, Email: yuanqi@stu.scau.edu.cn; Linlin Wang, PhD student, research interests: research on agricultural obstacles avoidance, Email: 576150990@qq.com; Kangting Yan, Master student, research interests: pesticide residue detection based on fluorescence spectroscopy, Email: keeping_ykt@163.com.

*Corresponding author: Ruichang Jia, $\mathrm{PhD}$, Lecturer, research interests: design and application of UAV. Mailing Address: College of Engineering, South China Agricultural University. Email: rcjia@scau.edu.cn. conveniently, paddy fields are generally distributed in areas with dense water networks, which are likely to cause lots of pesticides and fertilizers applied in paddy fields to enter the water. Excessively-applied fertilizers and pesticides in agricultural activities will also be spread to downstream water bodies by precipitation and runoff, which will further lead to serious pollution of rivers, lakes and other receiving water bodies ${ }^{[3-5]}$. The harm brought by the non-point source pollutants in the water environment of paddy fields involves the whole food chain centered on human beings, including eutrophication of water caused by excessive use of nitrogen and phosphate fertilizer, nitrate pollution of groundwater, and pollution of organochlorine and organophosphorus pesticides. At present, non-point source pollutions are highly random, extensively covered and often remain undetected for a long time, which makes it difficult to detect and control effectively. This paper focuses on non-point source pollution caused by excessive use of chemical fertilizers and pesticides in water environment of paddy fields, as well as studies and discusses its detection methods, especially fast and online treatment methods.

\section{Detection of water eutrophication in rice paddy fields}

2.1 Water eutrophication

As an important rice producing base in China, the southern 
area produces it in an intensive production mode that requires a large amount of fertilizer; however, the average utilization rate of nitrogen fertilizer is only $30 \%-35 \%[6]$, which leads to the loss of many nutrients from the paddy fields that stored water in long term, causing groundwater pollution, water eutrophication and pollution of surface water, etc. Water eutrophication, which is mainly caused by the agricultural non-point source pollution, is one of the severest problems of water environmental pollution nowadays. According to 《the First National Census on Sources of Pollution》, agricultural pollution sources have become the main source of Total Nitrogen (TN) and Total Phosphorus (TP) emissions, which are 2,704,600 tons and 284,700 tons, accounting for $57.2 \%$ and $67.4 \%$ of total emissions respectively. Therefore, it has become an important issue to control the agricultural non-point source pollution in the development of modern agriculture ${ }^{[7]}$. The process of water eutrophication is shown in Figure 1.

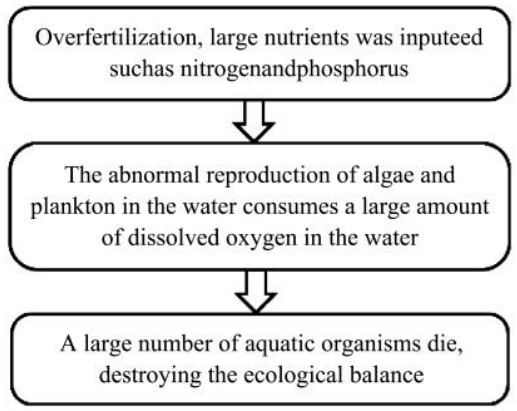

Figure 1 Diagram of the process of water eutrophication

During the process of rice planting, over-fertilization causes a large amount of nutrients such as nitrogen and phosphorus to enter a relatively slow-flowing water body, which further results in abnormal reproduction of algae, plankton, protozoa and bacteria in the water, thus more dissolved oxygen in the water is consumed, and a large number of aquatic organisms (such as fish) have died of it. As a result, the ecological balance of the water environment has been destroyed. Yang et al. ${ }^{[8]}$ points out in their investigation and analysis that the unreasonable or excessive use of agricultural materials such as pesticides, fertilizers and plastic films caused by the pressure of food security makes the pollutants penetrate into the nearby water bodies by precipitation or irrigation, and then results in water pollution and even eutrophication. Moreover, the loss of nutrients has been escalated the backwardness of fertilization technology, the disconnection of crop demand, the low utilization of agrochemicals and irrigation water, and the lack of public environmental awareness. The research of Zhang et al. ${ }^{[9]}$ shows that the core problem of water pollution in China is nitrogen and phosphorus eutrophication in water bodies; and the water bodies in southern China have been seriously polluted due to the rice planting - the loss of nitrogen and phosphorus spawned by the livestock rearing and farming contributes much more to the nitrogen and phosphorus eutrophication in the water bodies than the point source pollution produced by the domestic and industrial sewage, thus the water eutrophication comes into being. The research results of $\mathrm{Hu}$ et al. ${ }^{[10]}$ indicates that the odds of water eutrophication were $64 \%, 68 \%$ and $38 \%$ respectively when the nitrogen, phosphorus and both of them increase in the paddy fields.

Guo et al. ${ }^{[11]}$ studied the distribution of various types of non-point source pollution loads of rice in the Taihu Basin, and the results demonstrated that nitrogen emissions from paddy fields accounted for $72.9 \%$. Also, because algae can directly fix nitrogen from the air, the nitrogen decomposed by microorganisms after some algae's death can be reused by other algae, and phosphorus can limit the healthy development of freshwater ecosystems, the algae in water will also increase and reproduce when phosphate concentration raises. Paddy fields, the largest water-stored part in the farmland, its loss of nitrogen and phosphorus must not be underestimated. Therefore, it is necessary to limit the nitrogen and phosphorus in the paddy field and prevent water eutrophication.

\subsection{Determination methods of Total Nitrogen in water}

Total Nitrogen (TN) is the sum of various forms of organic nitrogen and inorganic nitrogen in water, and it is one of the important indicators to measure the eutrophication status of water bodies $^{[12]}$. According to China's national standard - alkaline potassium persulfate digestion UV spectrophotometry, potassium persulfate can be decomposed in aqueous solution above $60^{\circ} \mathrm{C}$ to produce potassium hydrogen sulfate and atomic oxygen, the latter can transform the nitrogen element of the nitrogen-containing compound into nitrate in the water sample, so that the total nitrogen concentration can be detected by ultraviolet spectrophotometry ${ }^{[13]}$.

Yang et al. ${ }^{[14]}$ adopted high temperature oxidation chemiluminescence assay (HTO - CL) to determine the total nitrogen concentration in the water. The result shows that its precision, accuracy and recovery are superior to traditional ones. This method meets the concept of automatic and rapid detection online, as it does not need pre-treatment or chemical reagents, with high analytical efficiency and automation, wide linear detection range. However, this method requires an online measuring instrument, a high-temperature oxidation furnace and other test instruments, and it is difficult to rapidly detect the total nitrogen in paddy fields. Liu et al. ${ }^{[15]}$ verified the feasibility of testing total nitrogen by continuous flow analysis. Their experiment indicates that this method is not only highly accurate with better relative standard deviation than the national standard analysis method, but also is easy to operate and able to keep on automatic analysis in a high speed with low cost of reagent and samples, skipping the tedious process of manual operation., so as to improve the efficiency, which is suitable for detecting a quantity of samples. However, the process of blending samples to standard solutions is relatively complicated, and it can only be automatically tested in the laboratory. Further research is needed for outdoor field testing. This year, Cui et al. ${ }^{[16]}$ used online digestion-gas phase molecular spectroscopy to detect total nitrogen in water, which overcomes the shortcomings of long pretreatment time, tedious manual operation and high requirements for the reagent. This method is especially suitable for treating diluted high-concentration water samples in a relatively higher automation level. But using an autoclave to digest cannot satisfy the determination of rice field under normal temperature and pressure.

To some extent, methods above have improved the disadvantages of traditional methods such as complicated operation and long experimental time, their simple operation helps to reduce staffs effectively, and to improve the efficiency to a certain extent on the premise of ensuring precision and accuracy. $\mathrm{Li}^{[17]}$ developed an online automatic monitoring instrument for measuring total nitrogen in water by using ultraviolet ozone combined with traditional methods. The instrument can digest the water quality under normal temperature and pressure without adding chemical oxidant. However, its high requirement for water sample pretreatment, water for experiments, and reagent storage, makes it not suitable for detecting the environment of paddy field rapidly. Wang ${ }^{[18]}$ developed a software system that 
combines PLC control with GPRS remote transmission monitoring based on the hardware of $\mathrm{Li}^{[17]}$. The integrated system can minimize mutual interference, manage and replace easily, and is more convenient and quick to operate. The interface design of LabVIEW software is convenient for real-time online viewing by remote-operating observers, which is suitable for continuous online monitoring of water quality. This system has great reference value for real-time rapid online detection and even remote control of rice field's water quality, and the reduction of hardware volume will become the key to whether this system can be used in the field. Han et al. ${ }^{[19]}$ developed a total nitrogen online analyzer based on sequential injection analysis technology, which combined with photoelectric detection system on the basis of traditional digestion methods to accurately and steadily monitor the concentration of total nitrogen online. The development and utilization of photoelectric detection unit is worthy of reference. The development of these automatic online monitors will lay a certain foundation for the study of relevant sensors for detecting total nitrogen in paddy fields.

In addition, most of the organic nitrogen in total nitrogen exists in the form of ammonia nitrogen. $\mathrm{Wu}$ et al. ${ }^{[20]}$ proposed a dual wavelength improving method for determine ammonia nitrogen. This dual-wavelength spectroscopy method removes the pretreatment of water sample, flocculation and precipitation, and is especially suitable for rapidly detecting ammonia nitrogen concentration in a quantity of surface water samples. It is left to be further explored and discovered the linear relationship between ammonia nitrogen and total nitrogen in rice fields, and how to use this method to rapidly calculate the total nitrogen concentration.

\subsection{Determination methods of total phosphorus in water}

Total Phosphorus (TP) is defined as the sum of orthophosphates, concentrated phosphates and organically bound phosphorus $^{[21]}$. In recent years, increasing phosphorus concentration is considered to be the main cause of algae reproduction and eutrophication. To determine total phosphorus in water quality, China's national standard, Ammonium Molybdate Spectrophotometric Method stipulates that potassium persulfate (or nitric acid - perchloric acid) should be used as the oxidant to digest the unfiltered water sample, in which the phosphorus will be oxidized into orthophosphate; and then in the acidic medium, orthophosphate and ammonium molybdate will react to form a molybdenum heteropoly acid, which will be immediately reduced by ascorbic acid to form a blue complex for spectrophotometric determination of total phosphorus concentration ${ }^{[22]}$.

Ion Chromatography (IC) is a method for calculating the total phosphorus and total nitrogen content by using liquid chromatography to detect the content of PO43- and NO3- in water by analyzing the ion-type compound ${ }^{[23,24]}$. The chromatogram of the water sample processed by ion chromatography is shown in Figure 2. Liu et al. ${ }^{[25]}$ used ion chromatography and spectrophotometry to determine the content of nitrite in water for comparative analysis, which manifested that there was no significant difference between the results of these two methods. The spectrophotometry can determine accurately when the concentration of nitrite is low in the water, while the ion chromatography works better when it is higher. This method is more suitable for detecting a large number of samples. This research can also be used to detect total phosphorus based on phosphate ions. Yang ${ }^{[26]}$ used ion chromatography to determine the total phosphorus total nitrogen content. The data obtained showed that the calibration curve of total phosphorus has a wider linear range. Also, this method allows high recovery rate, good repeatability, simple and convenient operation. But it requires certain treatment for water samples, and the high requirements for oxidative digestion as well as the complicated working conditions of the instrument make it not suitable for determining outside the laboratory. Liu et al. ${ }^{[27]}$ discussed the working conditions of inductively coupled plasma atomic emission spectrometry (ICP-AES), which has the advantages of relatively simple detection process, high accuracy and precision, low detection limit, fast determination speed and wide determination range. It can not only directly determine the content of inorganic phosphorus, but also detect the content of organic phosphorus in sewage simultenously, which can simplify the complicated steps of digestion process, eliminate errors caused by multi-steps operation, and avoid secondary pollution to the environment. However, the water used in this experiment is deionized water whose demand of the solution's ratio is relatively high. Therefore, it is not suitable for operation in a simple outdoor environment and rapid detection of total phosphorus in paddy fields. $\mathrm{Li}^{[28]}$ analyzed the main points of flow injection analysis for the detection of total phosphorus. The flow injection analyzer has the functions of automatic sampling, automatic dilution of standard solution, and online digestion, which reduce complicated manual operations and realize full automatic processing. This method is suitable for batch online detection of total phosphorus. However, the pipeline of this analyzer is relatively thin, and it is not suitable to determine water samples containing large particles or suspended particles. Therefore, it is necessary to filter the sample when detecting the water quality of the paddy field, and the instrument is not convenient for field monitoring and cannot determine so fast as require.

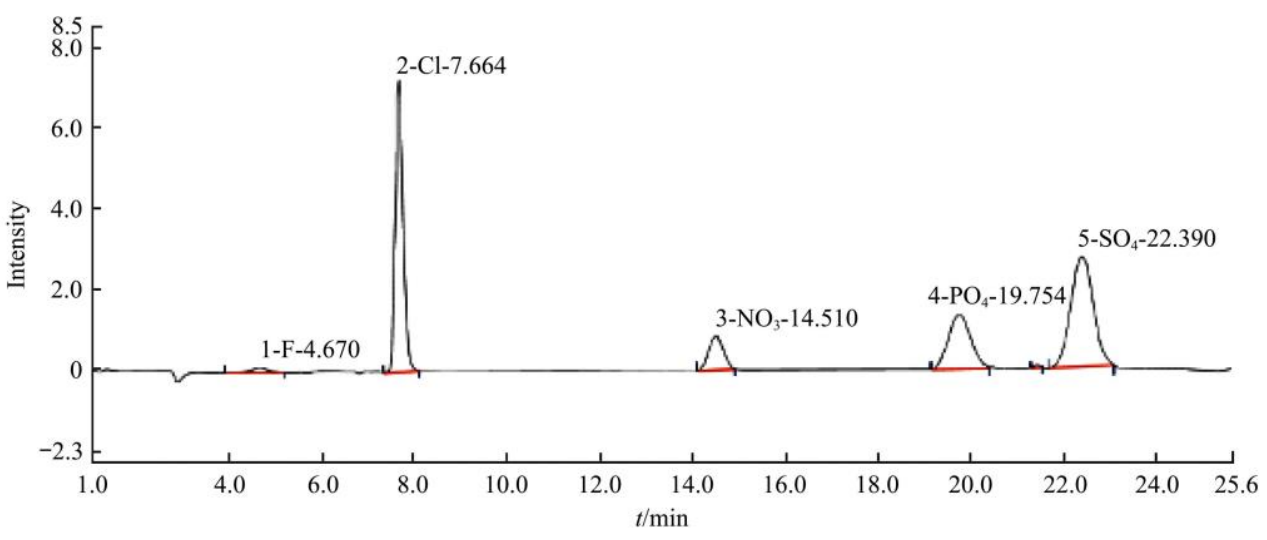

1. Fluoride 2. Chloride 3. Nitrate 4. Phosphate 5. Sulfate

Figure 2 Ion chromatography water sample separation chromatogram ${ }^{[23]}$ 
In recent years, with the combination of some new technologies and national standard methods, the research progress has been greatly improved. Zhu et al. ${ }^{[29]}$ catalyzed the degradation of chlorpyrifos, a typical organophosphorus pesticide, by using photocatalytic microreactor with nanometer Ti $\mathrm{O} 2$ coated microfluidic chip. The reaction time under ideal conditions is only $30 \mathrm{~s}$, which greatly reduces the time required for sample processing during total phosphorus detection; then the national standard method is used to measure the absorbance of ions to obtain the total phosphorus content, so as to establish A micro-analysis system for on-line detection of total phosphorus, and realize high-efficiency photocatalytic degradation of organic phosphorus in water samples, as well as analyze total phosphorus online by using an ultraviolet flow cell detector (Figure 3). Lu et al. ${ }^{[30]}$ proposed a system for on-line monitoring of total phosphorus combined with traditional spectrophotometry based on micro-control technology. The establishment of various modules is closely related to system control processes, which makes the system smaller and more space-oriented. It has the advantages of high utilization rate, fast detection speed, low reagent consumption and small amount of waste liquid. It is also suitable for laboratory and on-site monitoring, and can realize real-time detection of total phosphorus in water quality. The next step is to reduce the dead volume of these detectors or detection systems to further shorten the detection time. In the future, based on these studies, the corresponding detection sensors can be developed to achieve real-time fast online monitoring.

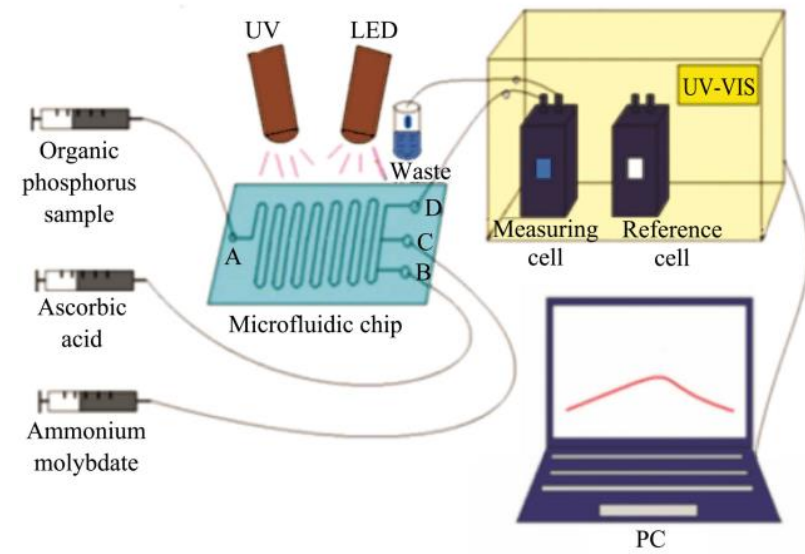

Figure 3 Schematic diagram of total phosphorus online monitoring system ${ }^{[29]}$

\subsection{Monitoring methods of water eutrophication}

The eutrophication of natural water bodies results in the proliferation of algae substances. The algae contains stable and quantitative chlorophyll-a and is easy to measure manually. Therefore, the concentration of chlorophyll-a can be used as an important parameter reflecting the degree of eutrophication of water bodies ${ }^{[31]}$. Compared with traditional manual measurement, satellite remote sensing technology has the characteristics of real-time monitoring, wide viewing angle, fast and convenient, etc., and is more suitable for monitoring this large-scale complex water body $^{[32]}$.

Zhang et al. ${ }^{[33]}$ used remote sensing images to select appropriate test areas and obtained a chlorophyll concentration evaluation method suitable for the characteristics of the Yangtze River estuary to further obtain the eutrophication characteristics of the estuary. Peppa et al. ${ }^{[34]}$ combined satellite image data and chl-a detection algorithm to study the degree of eutrophication of Lake Pamvotis in Ioannina, Greece, and it is easy to estimate eutrophication areas and coastal areas that may affect the lake through canals. It can be seen that remote sensing and satellite technology are important in monitoring water eutrophication, but in order to improve the accuracy of inversion, hyperspectral remote sensing and hyperspectral remote sensing should be developed, and the accuracy of remote sensing data processing should be ensured. In addition, Lan et al. ${ }^{[35]}$ proposed the concept of precision agriculture aviation: "air, space and ground" mutual cooperation, that is, satellite remote sensing and ground remote sensing collect agricultural information with geographical locations, and then formulate different operation prescription maps based on different information. Then UAVs and ground machinery are used to accurately apply pesticides or broadcast. This concept can be used to combine low-altitude remote sensing and high-altitude remote sensing to quickly obtain relevant information about rice fields and water bodies, and then compare laboratory test results to establish inversion models to achieve faster and more convenient purposes (Figure 4).

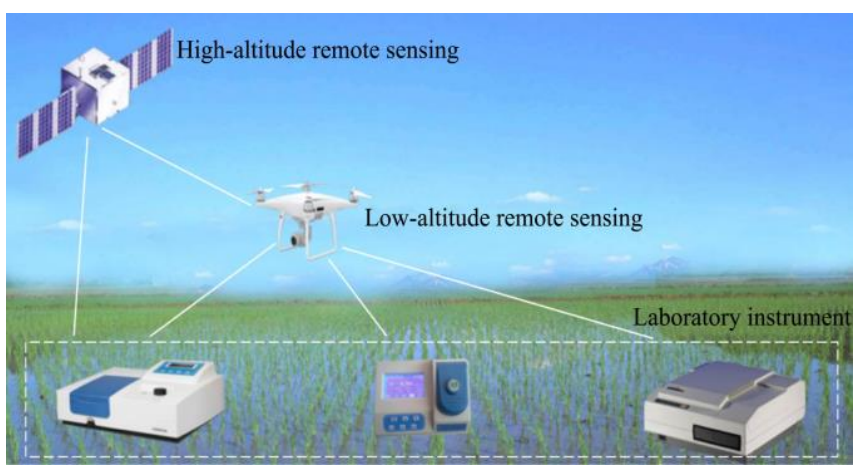

Figure 4 Theoretical concept system diagram

\section{Detection of groundwater nitrate contamination}

\subsection{Nitrate contamination of groundwater}

There are more than a dozen nutrients necessary for rice growth, but nitrogen, phosphorus and potassium are greatly absorbed but not insufficient in the soil. The loss of nitrogen fertilizer applied in rice production is up to $30 \% \sim 70 \%$. Because the crops cannot fully absorb and utilize, and nitrate ions cannot be adsorbed in the soil, the nitrate in the soil is leaching into the downstream water during rainfall and irrigation, which causes nitrate contamination in groundwater. In recent years, studies by many scholars have shown that nitrate pollution in groundwater is widespread worldwide, and the concentration of nitrate in groundwater is increasing year by year ${ }^{[36,37]}$. However, the areas with high agricultural intensification and great use of nitrogen fertilizer in China are facing serious nitrate pollution in groundwater. A sample survey conducted by the Chinese Academy of Agricultural Sciences since 1994 reveals that $20 \%$ of the groundwater nitrate content in the intensive fertilizer-using area in northern China exceeds the limit of nitrate content in drinking water in China. Some studies ${ }^{[38]}$ indicates that in Huanghuaihai area, the middle and lower reaches of the Yangtze River, the northeastern region, the northern plateau region and the southwestern region, the average quantity of chemical fertilizers application in the productive process of japonica rice are respectively $472.09,357.15,311.222,381.99$ and $365.49 \mathrm{~kg} / \mathrm{hm}^{2}$, which have exceeded the internationally recognized safe fertilizer application quantity (Figure 5). Compared with other rice producing countries, the unreasonable application of chemical fertilizers in rice production is particularly serious in China. 


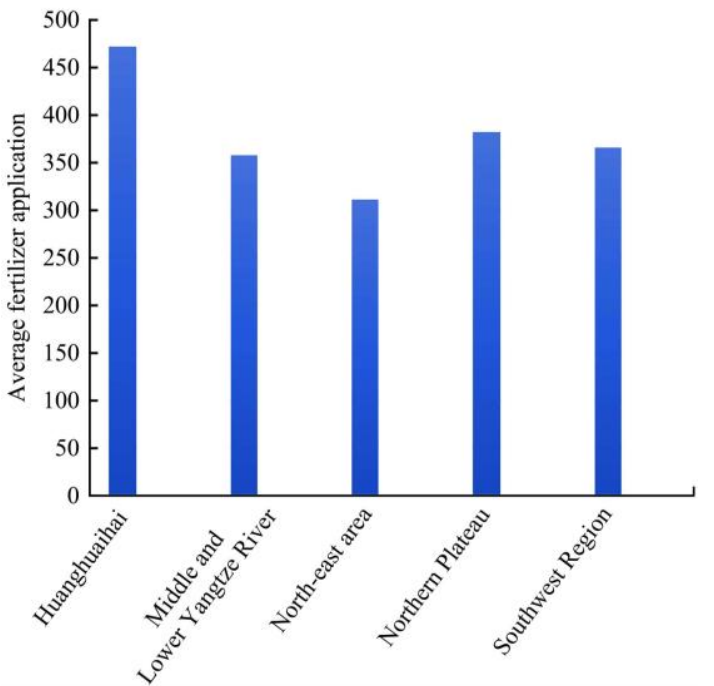

Figure 5 Histogram of average fertilizer application amount in various regions

The dense water networks of rice planting area in southern China has also aggravated nitrate pollution in water bodies in the southern regions. Taking rice production in southern China as an example, the application amount of nitrogen and phosphorus fertilizer is higher than that in California, USA, where the climate is dry and the soil fertility is low, which indicates the unscientific use of chemical fertilizer in rice cultivation in China. If nitrate-contaminated water is used to irrigate vegetables and other crops, they will absorb a lot of nitrates, which will cause secondary pollution. The accumulation of nitrate nitrogen in soil was positively correlated with the content of nitrate nitrogen in groundwater and vegetables, indicating that the nitrogenous fertilizer input in the intensive planting area was overly excessive, which not only caused nitrate pollution in groundwater, but also caused excessive nitrate content of plants ${ }^{[39]}$. In addition, the lower content of organic matter in soil and sediment is always accompanied by weaker denitrification, which is not conducive to the natural attenuation of NO3- in groundwater. As a result, the nitrate concentration will gradually accumulate ${ }^{[40]}$.

Although nitrate itself is not toxic, it can be reduced to nitrite, which will cause poisoning if people ingests 0.3-0.5 grams of it, and 3 grams of it can lead to death. What is worse, under acidic conditions, nitrite reacts with secondary amines in the human body to form strong carcinogenic nitrosamines, one of the three major cancerous substances in the world that can seriously endanger human health. Therefore, we need more researches on non-point source pollution of rice fields, so as to implement the strategy of sustainable development of agriculture in China.

\subsection{Determination methods of nitrate}

The common detection methods of nitrate include spectral method, chromatographic method and electrochemical method, among which spectrophotometry, ion chromatography and ion selective electrode method are most commonly used ${ }^{[41,42]}$, and spectrophotometry is the most basic method.

Zhang et al. ${ }^{[43]}$ adopted a dual system to simultaneously analyze anions and cations on the basis of ion chromatography. Samples can be directly injected after sampling and filtering, so the process is simple, quick, sensitive and accurate, with a wide linear range. Compared with the traditional method, this method uses an automatic eluent generator, which only needs pure water to produce an eluent safely and non-toxically. However, the chromatographic instruments are so large and expensive that they are for laboratory use only, and requirement for the high accuracy of the needed instruments such as ion separation columns prevent the experiment from applying in the simple environment, thus the fast online detection cannot be achieved in the fields. The rapid on-line continuous monitoring of nitrate ion concentration mainly utilizes one of the electrochemical method the ion selective electrode method, which employs the principle of potential sensing: the tip of the electrode in contact with the water sample is usually a sensitive membrane that is selective for specific ions., so the change in ion concentration inside and outside the membrane creates a potential difference on the surface of the sensitive membrane, which can then be converted to the concentration of the corresponding ion according to the Nernst equation. The first application of the method was to analyze specific ion concentrations in the laboratory. The ion electrode produced by WTW Company in the United States can be directly immersed in water to detect the concentration of ammonia nitrogen and nitrate nitrogen $^{[44]}$ (Figure 6). However, this method is more expensive, and there are also some problems such as easy cross-contamination of samples, manual -operating calibration, and unstable potential response curve ${ }^{[45]}$.

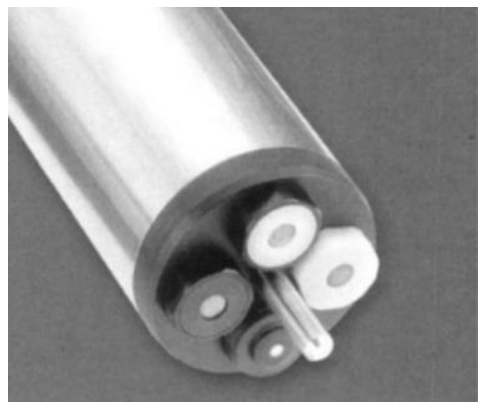

Figure 6 WTW new ion composite electrode ${ }^{[44]}$

Aiming at solving the problems above, Zhang et al. ${ }^{[46]}$ developed a fluid flow control system to detect the nitrate rapidly, in which they used polypyrrole polymer as sensitive membrane materials for sensing unit. Its combination with the underlying data collector can realize the automatic collection, storage, display and transmission control of the detected samples' data. Also, with its small volume, each sample can be processed in only six minutes. Hao, Shuai et al ${ }^{[47,48]}$ take the Gallery automatic water quality analyzer combined with traditional spectrophotometry to determine the nitrate in water. This automated-program-controlled instrument is easy to operate, no need to rinse and calibration, and cost fewer samples and reagents. It can be unattended during the detection process and operated automatically in real time, which is more suitable for rapid detection of many samples. The above two analysis systems are mainly applied to the detection of surface water, and the application in the paddy water environment is still in the initial stage of experimental exploration. For the research direction of sensors for detecting nitrates, Yu et al. ${ }^{[49]}$ designed a new type of planar electromagnetic sensor for online detection of water nitrate concentration, adopting the impedance of the sensor to reflect the concentration of water nitrate. The simulation results signify that the discrimination of different nitrate concentration solutions is very good, and it is a suitable method for online detection. Applying this sensor to the farmland scene, it can be quickly and continuously measured, laying a foundation for the research of other sensors.

In addition, the use of remote sensing to obtain optical reflectance data to track and detect the content of nitrate in groundwater or soil in a certain area is one of the hot spots of 
detection methods. The use of remote sensing technology can break through the limitations of space and time and prevent nitrate pollution. Better tracking and analysis of the situation ${ }^{[50-52]}$. Ag. Filintas et al. ${ }^{[53]}$, in order to record and evaluate the regional trend and occurrence of nitrate in groundwater in the agricultural basin of central Greece, combined with remote sensing satellite images to model the waste and fertilizer load in the study area, and on this basis Nitrate pollution in the watershed of the agricultural ecosystem was studied and evaluated. The above results show that the use of remote sensing information and geographic information systems to model and map groundwater nitrate pollution constitutes an important research tool that can provide reference for environmental policy measures.

\section{Detection of organochlorine pesticide pollution}

\subsection{Organochlorine contamination}

Of all the pollutants released into the environment by humans each year, the most dangerous are persistent organic pollutants (POPs). POPs are a general term for organic pollutants synthesized by humans, with four characteristics of long-term residual, bioaccumulative, semi-volatile and highly toxic ${ }^{[54,55]}$. Persistent organic pollutants are extremely difficult to degrade and can exist in nature for a long time. They are continuously enriched in living organisms through the amplification of biological chains, causing great harm to the ecological environment ${ }^{[56]}$. Due to the abundant water environment and warm conditions in the growing environment of rice, there will be more diseases and insect pests than other crops, and the application of chemical pesticides will increase correspondingly. Organochlorine pesticides applied in rice paddies are one of the major categories of pops. The persistent harm caused by such pollutants to the environment has drawn more and more attention from various countries. In May 2001, the United Nations adopted the Stockholm Convention on Persistent Organic Pollutants, which entered into force in China on November 11, 2004. There are 12 POPs listed in the first controlled list of the Convention, 9 of which are organochlorine pesticides, including DDT pesticides widely applied in paddy fields in China (Figure 7). In 2013, China further approved the elimination or restriction of 10 POPs such as $\alpha-\mathrm{HCH}^{[57]}$. At present, the POPs Convention prohibits the production and use of chemical substances to increase to $21^{[56]}$.

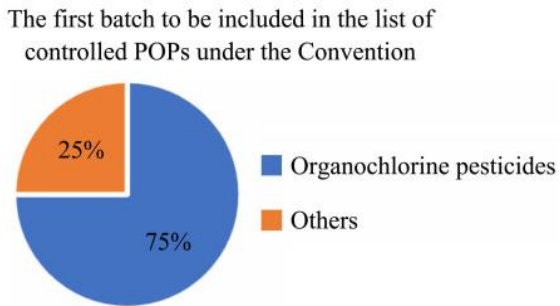

Figure 7 Pie chart of controlled POPs list

During 1950s to 1970 s, China had industrially produced six organochlorine pesticides such as DDT, toxaphene, hexachlorobenzene, chlordane, heptachlor and mirex. The total production of hexachlorobenzene and DDT in China has reached 4.9 million tons and 460,000 tons respectively, accounting for 33\% and $20 \%$ of the world's production ${ }^{[58]}$. Organochlorine pesticides, as persistent organic pollutants, are extremely stable and insoluble in water, but they are highly fat-soluble and easily enter organisms, including human adipose tissue; moreover, they cannot be monitored when their containments are low in the atmosphere, water and soil, but they still can enter the plants or lower organisms through these media, and then scale up throughout trophic level. What is even more frightening is that it has a certain volatility and can be transported globally. For example, the concentration of POPs is found in water samples from the Taihu Lake region and the Tianjin coastal region. The sediments in the Hudso River and the Humber River in the United Kingdom are also highly concentrated ${ }^{[54,55]}$; 14 kinds of organochlorine pesticides such as HCHs, DDTs and endosulfan II were detected in the tissues of the mites on the migration route of East Asia-Australia, among which $\alpha-\mathrm{HCH}, \beta-\mathrm{HCH}$ and $\gamma-\mathrm{HCH}$ were checked out. The detection rates of p,p'-DDE, endosulfan II, endosulfan sulfate and/or p,p'-DDT are all $100 \%^{[59]}$

Although organophosphorus pesticides are the dominant pesticides in China at present, because a large number of organophosphorus pesticides with harmful chemical characteristics have been widely used in China in history, they will continue to exist and accumulate in China's environment for a long time, and they are still detected to varying degrees in various soil and water environments in China ${ }^{[60,61]}$. In June 2009, Chen $^{[62]}$ collected 160 samples from farmland soil in Hunan Province. The study shows that $\mathrm{HCH}$ residues in rice soil were the most serious, and a small amount of organochlorine was absorbed by rice in the digestion process year after year, which caused inevitable damage to animals and humans through the food chain. Ding et al. ${ }^{[63]}$ collected 10 surface water samples and 7 surface sediment samples from Nansha Mangrove Wetlands in Guangzhou, and determined the content of organochlorine pesticides (OCPs) by GC-ECD in March 2015. The results show that the ecological risk of OCPs in water is small, but the OCPs in sediments contain more historical residual components, which have higher ecological risks and greater potential for secondary sources of water pollution that may harm mangrove ecosystems.

\subsection{Detection methods for organochlorine pesticides}

The concentration of organochlorine pesticides in the environment is very low, while the concentration of interfering substances in the environmental matrix is very high. So an effective method for the separation, enrichment and monitoring of trace organochlorine pesticides is needed. Common detection methods for organochlorine pesticides include Gas Chromatography (GC), Liquid Chromatography-Mass Spectrometry (LC-MS) and Gas Chromatography-Mass Spectrometry (GC-MS) ${ }^{[64-66]}$. Currently, the commonly used treatment methods in environmental samples include liquid-liquid extraction, soxhlet extraction, and solid-phase extraction, etc. ${ }^{[67]}$. Although these pretreatment methods are mature and stable, they are time consuming, labor intensive, and consume a large amount of toxic and harmful organic reagents, which is not suitable for online detection. The GC-MS method has higher sensitivity, lower detection limit, and relatively reliable analytical data, and is widely used for trace and ultra-trace analysis of organic substances in environmental samples ${ }^{[68]}$. However, the instrument is large and expensive, and the operation level is high, and it fails to realize online and on-site detection of organochlorine pesticide residues in water bodies.

With the continuous development and progress of modern science and technology, the research of sensor is favored by many researchers. As early as 2007, Yang et al. ${ }^{[69]}$ studied the surface acoustic wave DDT organochlorine pesticide immunobiosensor. As a new type of piezoelectric biosensor, surface acoustic wave sensor uses surface wave as a means of monitoring. The surface oscillator completes the biochemical reaction to the conversion of 
electrical signals, combined with immunoassay technology and piezoelectric sensor technology, requires a detection cell, and still belongs to the static laboratory detection method. Zhou ${ }^{[70]}$ combined a nanostructured $\mathrm{ZnO}$ sensor and chromatographic separation technology to develop a portable instrument for detecting POPs, which effectively solved the problem that the chromatographic instrument is too large to be detected on site. However, the control of the volume of the instrument is not ideal, and it is only subject to the detection of a substance in the nanosensor, which cannot be quantitatively detected. In the future, the volume of the instrument and the type of the detected substance should be optimized and improved to improve the feasibility of rapidly detecting organochlorine pesticides in rice fields. Jiang et al. ${ }^{[71]}$ summarized the research progress of electrochemical sensors on polychlorinated biphenyls. The characteristics of simple, rapid, specific, non-polluting and real-time detection are in line with the concept of rice field environmental testing. However, most of the tests are currently in basic application research and are limited to indoor scenes. The instability, non-uniformity of the electrodes, the unqualified detection environment, the limitation of detecting single pollutants, and the inactivation of biomolecules need to be solved one by one.

The application of sensors has improved the detection technology of organochlorine to a certain extent. At the same time, the development of remote sensing technology provides an important means for evaluating the detection of organic chlorine pollution. Muhammad A. El-Alfy et al. ${ }^{[72]}$, in order to assess the content of toxic heavy metals and organochlorine pesticides (OCPs) in water bodies, sediments and reeds in freshwater and marine environments in the Rosetta area,used remote sensing and geographic information system technology to conduct a spatial assessment of potential pollution sources. Studies have shown that the combination of remote sensing and chemical analysis can provide effective data support for the regional and economic evaluation of environmental toxicity at the freshwater-saltwater interface.

\section{Detection of organophosphorus pesticide pollution}

\subsection{Organophosphorus contamination}

The growth of rice requires adequate water resources, warm climate and appropriate light. Such environmental condition makes it troubled by diseases, pests and weeds more frequently than other crops, leading to the use of various chemical pesticides. Since organophosphorus pesticides were banned in 1980s, organophosphorus pesticides are the most widely used pesticides in China. Organophosphorus pesticides (OPPs) are organic compound pesticides containing phosphorus, which are generally oily or crystalline, and industrial products are light yellow to brown, mostly with garlic odor. Organophosphorus pesticides (OPPs) are organic compound pesticides containing phosphorus, which are generally oily or crystalline, and their industrial products appear to be light yellow to brown, mostly with garlic odor. It is generally insoluble in water, and is easily soluble in organic solvents such as benzene, acetone, and oils. It is relatively stable to light, heat, and oxygen, and is easily decomposed and destroyed by alkali. At present, there are more than 150 organophosphorus pesticides in the world, and the degradation products of some organophosphorus pesticides are much more toxic than the mothers and are more likely to migrate in the environment ${ }^{[73]}$. Therefore, the impact and harm of organophosphorus pesticides on human health and water resources can never be ignored as they are widely used in rice production. Taking the pollution of organophosphorus pesticides on the water environment of rice field as an example, organophosphorus pollution can be caused by the excessive application of organophosphorus pesticides in the rice field and the applied pesticide into the downstream water body through runoff, leaching, wet and dry settlement and other ways At the same time, due to the evaporation of farmland water, pesticide particles and steam used in rice paddies are emitted in the air, drifting in the wind, and can return to the surface water environment through precipitation, resulting in large-scale organic phosphorus pollution in water bodies. The pollution path is shown in Figure 8. Moreover, the persistent, accumulative and semi-volatile characteristics of organophosphorus pesticides not only make it pollute water bodies, but also preserve them in soil and other environments for several years or even longer, and accumulate through the biological chains to harm advanced animals such as human beings unconsciously, and their wide-ranging transfer further expands the damaged area ${ }^{[74]}$.

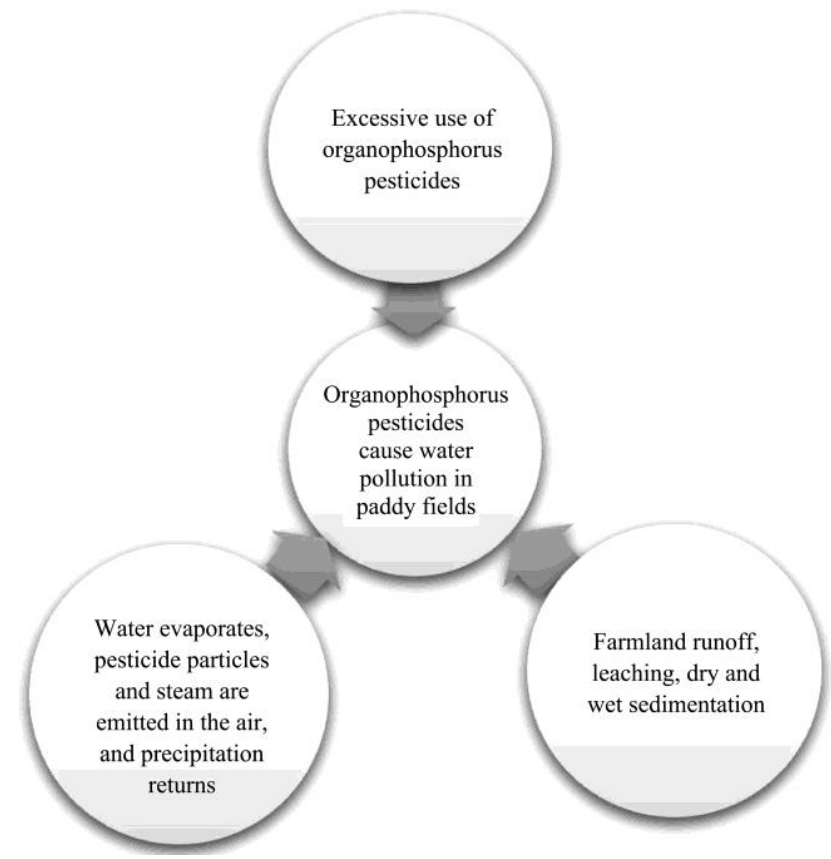

Figure 8 Pollution Approach in Rice paddies of Organic Phosphorus Pesticide

In general, pollutants have a greater impact on lower organisms than on higher organisms, while vertebrates are more tolerant and less sensitive to organophosphorus pesticides ${ }^{[73,75]}$. However, in the case of humans, organophosphorus pesticides can enter the human body through the digestive tract, respiratory tract and intact skin and mucous membranes, and are distributed in various organs. They form phosphorylated cholinesterase with cholinesterase, which inhibits acetylcholinesterase, and then leads to cognitive and neurobehavioral abnormalities, malformations and endocrine disorders, causing acute harm to humans and even increasing the risk of cancer ${ }^{[76]}$.

In the early stage, some organophosphorus pesticides with higher toxicity and more residues have been or are being eliminated. Since January 1, 2007, 5 high-toxic pesticides-methamidophos, monocrotophos, parathion, methyl parathion and omethoate have been completely banned from domestic sales and use. However, China's pesticide market is so complicated that some of the eliminated varieties continue to be used in some places driven by interests. The progress of promoting and applying bio-pesticides in China is slow because the effective active 
ingredients of bio-pesticides are complex and susceptible to environmental factors, the bactericidal spectrum and insecticidal spectrum are relatively narrow, and bio-pesticide lacks market competitiveness, organophosphorus pesticides still have a large market in the future for the use of crops such as rice fields. In recent years, China has also vigorously carried out the development and promotion of high-toxic organophosphorus pesticide substitutes. For example, chlorpyrifos is an important alternative to highly toxic organophosphorus pesticides which is used for the control of rice planthoppers and rice leaf roller, but still belongs to a low-toxic organophosphorus pesticide. It is toxic to bees, fish and other aquatic organisms and silkworms. In addition, some farmers in the process of using one-sided pursuit of rice production, blindly over-use of pesticides, all of the above will cause a widespread existence of organic phosphorus pollution for a long period of time in the future. Organophosphorus pesticides have become the most important toxic pollutants in rice field discharge water. Its effective and rapid detection is a key means to protect the environmental safety of paddy fields and downstream water bodies.

\subsection{Testing methods for organophosphorus pesticides}

The traditional method for the detection of organophosphorus pesticides in water is spectrophotometry. At present, according to the chemical and toxicological properties of organophosphorus pesticides, the detection methods are mainly divided into chromatography, rapid detection and spectroscopy.

Chromatography includes gas chromatography (GC), gas chromatography-mass spectrometry (GC-MS), high performance liquid chromatography (HPLC), liquid chromatography-mass spectrometry (LC-MS), high performance liquid chromatography-tandem Mass spectrometry (HPLC-MS) ${ }^{[77-82]}$. Its outstanding sensitivity and high accuracy of quantitative analysis allow it to be the main method for monitoring organic phosphorus in the monitoring and inspection department, and it is also the most classical and widely used instrumental analysis method for organophosphorus pesticides. However, the pretreatment process of these methods is cumbersome and complicated, the detection cycle is long, the requirements for the detection instrument and the detection environment are high, and the professional is required to operate, which cannot meet the requirements of modern agricultural rapid and on-site detection.

Rapid detection methods include immunoassay, enzyme inhibition and biological or chemical sensor technology. Immunoassay is convenient, rapid, specific, sensitive, safe and reliable with low analysis cost, which has become a technology for rapid detection of organophosphorus pesticide residues ${ }^{[83]}$. According to the different antigen or antibody markers, it is divided into radioimmunoassay method, enzyme-linked immunosorbent assay, chemiluminescence immunoassay, fluorescence immunoassay and gold-labeled immunoassay ${ }^{[84]}$. Each method has certain limitations that the protection of radioimmunoassay and waste disposal are difficult, and the enzymes in the enzyme-linked immunosorbent assay are easily inactivated. Chemiluminescence immune systems have the disadvantages of short luminescence time, weak luminescence intensity and poor reproducibility ${ }^{[84,85]}$. The enzyme inhibition method is simple to operate and can be used for rapid and sensitive detection, which is often used in field detection and screening of a large number of samples. However, its sensitivity is not high and the repetition rate needs to be improved, so it cannot meet the requirements of low residue and quantitative detection ${ }^{[83,84]}$. Both of these methods provide theoretical basis for the research of biological or chemical sensors.

Biological or chemical sensor technology has become the central research target for the detection of organophosphorus pesticides due to its advantages such as simple operation, fast sensitivity, low cost, easy to carry, on-site and real-time monitoring, etc. ${ }^{[86]}$. The enzyme sensor mainly combines the enzyme inhibition method and the electrical current characteristics to detect the pesticide content ${ }^{[87]}$. The key to study this sensor is how to immobilize acetylcholinesterase on the electrode surface and maintain the original catalytic activity ${ }^{[88]}$. Wei, Yu, Zheng, Zhao and other researchers based on glassy carbon electrodes, carbon nanotubes, etc., using a variety of modification methods and adding functional groups to develop a variety of new modified materials to increase the fixation of the electrode to acetylcholinesterase ${ }^{[89-92]}$. Part of the AChE biosensor is shown in Figure 9.
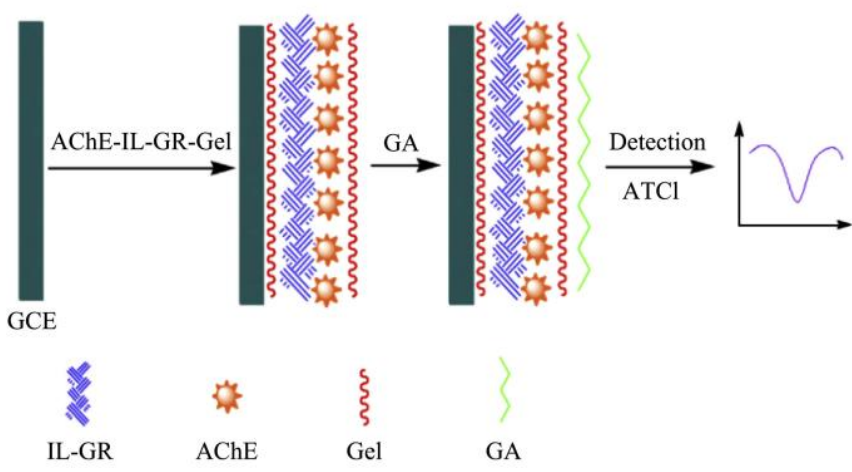

Figure 9 AChE biosensor production schematic ${ }^{[91]}$

Mishra et al. screened transgenic acetylcholinesterase on the basis of traditional acetylcholinesterase to enhance the binding of acetylcholinesterase to organophosphorus pesticides ${ }^{[93]}$. In addition to the single enzyme system, researchers such as Crew, Silletti and Zhang have also developed multi-enzyme system enzyme inhibition biosensors ${ }^{[94-96]}$, which expands the detection range of organophosphorus pesticides. The organophosphorus hydrolase biosensor has the advantages of high reaction specificity, mild reaction conditions and no stimulation, and can measure various organophosphorus pesticides such as chlorpyrifos, paraoxon, parathion ${ }^{[88]}$. Kim et al. ${ }^{[97]}$ immobilized the fusion protein of gold-binding peptide and organophosphorus hydrolase on the surface of gold electrode to prepare a low-cost single-use organophosphorus hydrolase biosensor, which promotes the combination of organophosphorus hydrolase and organophosphorus pesticides. Yan et al. ${ }^{[98]}$ prepared an organophosphorus hydrolase biosensor based on quantum dot technology, applied it to the residue detection of methyl parathion, and established a method for detecting methyl parathion residue in tap water. Natural organophosphorus hydrolase is not easy to obtain and store. It needs to be cultured from E. coli recombinants, and its stability at normal temperature is also increased. Therefore, the marketization of such sensors is difficult, and it cannot meet the conditions for online real-time monitoring of the concentration of organic phosphorus in water. Immunobiosensors are a class of biosensors that combine immunoassay technology with sensing technology. They are highly regarded for their specificity, low cost, and high throughput processing of samples. Liu et al. ${ }^{[99]}$ produced a novel multi-component analytical electrochemical immunosensor that can simultaneously measure paraoxon and endosulfan. Nowadays, research on nucleic acid aptamer sensors in the fields of chemistry, biomedicine and materials science has strong specificity, high 
affinity, easy preparation, easy modification, good stability and diversity of targets. But the application of pesticides is still in its infancy ${ }^{[100]}$. Moreover, biological or chemical sensors are susceptible to environmental conditions such as humidity and temperature, and biomaterials are easily deactivated, which hinders the marketization of sensors. Their application in rice fields is even rare.

Spectrometry has the advantages of simple operation, high efficiency, high sensitivity, fast analysis speed and simultaneous determination of various elements or compounds ${ }^{[84,101]}$. At present, the spectroscopy methods for detecting organophosphorus pesticides mainly include infrared spectroscopy, fluorescence spectroscopy and ultraviolet spectroscopy. Liu et al. ${ }^{[102]}$ used near-infrared spectroscopy to determine the application of trace organophosphorus pesticide chlorpyrifos in solution. The results show that by selecting the appropriate pretreatment method and the range of the spectral range analyzed, there is a good correlation between the predicted and chemical values of the sample during the prediction of the two different sample samples. Cao et al. ${ }^{[103]}$ and Yan et al. ${ }^{[104]}$ studied the absorption and refraction spectra of methyl parathion and dimethoate molecules of organophosphorus pesticides in the infrared band by terahertz time domain spectroscopy, providing useful parameters for the detection of pesticide molecules by terahertz technology. Chen et al. ${ }^{[105]}$ used Edinburgh FLS920P spectrometer to study three kinds of organophosphorus pesticides and concluded that they can produce strong absorption peaks and fluorescence peaks under the excitation of ultraviolet light, which can effectively detect the presence of organophosphorus pesticides. Ma et al. ${ }^{[106]}$ found the reflection spectrum of chlorpyrifos based on hyperspectral characteristic wavelength or characteristic band technology and established a quantitative model by combining a series of methods, proving that this method provides certain reference for the rapid detection of organophosphorus pesticides. Xing et al. ${ }^{[107]}$ explored the application of fluorescence probe in organic pesticides, which has high sensitivity, strong stability and simple operation. The interaction and fluorescence changes are shown in Figure 10. However, compared with foreign countries, there are few relevant reports and researches in China, and they have not really mastered the core technology. These findings provide assistance for the application of spectroscopy to the detection of non-point source pollutants in rice water environments, but there are also many deficiencies. It is often difficult to have a standard sample as a reference and to require that the composition and

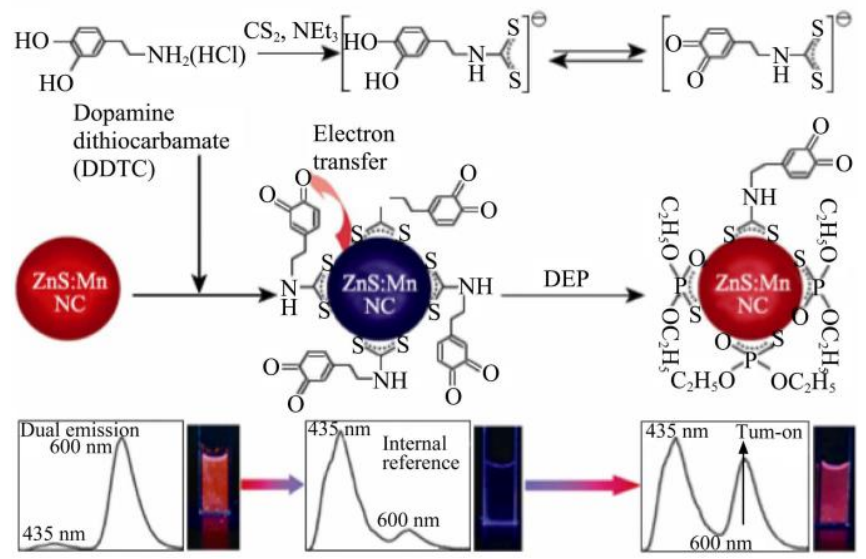

Figure 10 Interaction between fluorescent probe and organic pesticide and its fluorescence change ${ }^{[106]}$ structural state of the standard sample be substantially consistent with the sample being analyzed. Fluorescence spectroscopy is used to determine the influence of interference factors such as solvent, temperature, and $\mathrm{pH}$ of a solution. Many substances need to be added with a reagent to excite fluorescence. At present, the spectroscopy method still has a certain distance from the on-line detection level of paddy field water quality.

\section{Discussion and conclusions}

In order to more intuitively reflect the advantages and disadvantages of each method, a comparative analysis of the above-mentioned various types of pollutant detection methods is carried out, and it is judged whether it is suitable for the detection of non-point source pollutants in rice fields, as shown in Table 1.

With the increasing non-point source pollution in rice fields, the analysis and detection of non-point source pollutants is particularly important. Therefore, it is necessary to find a convenient and quick detection method currently. At present, there are many studies on river water quality, but there are few reports on non-point source pollution in rice field water environment. The traditional physical and chemical testing methods for water quality need to be sampled back to the laboratory, which is time-consuming and labor-intensive, has a large workload, low efficiency and poor timeliness. When it is specific to rice fields, it cannot meet the precise production requirements of modern agriculture. In summary, the research direction and priority of rice field water detection in the future will focus on the following aspects:

(1) Improving fast online real-time monitoring technology. Most of the research is carried out in the laboratory. It takes a long time to pretreat and decompose, and the long distance between field and the laboratory makes it impossible to monitor the change of pollutant content in the paddy field in real time online, so the rapid and online detection method can greatly improve the efficiency. And need to strengthen the precise management of the use of equipment and monitoring process.

(2) Developing water contamination detection sensors. At present, different detection of pollutant uses different laboratory instruments, which too large to use in the field. The development of relevant detection sensors can not only be carried lightly, but also can quickly acquire real-time data in rice fields. The key point is that sensor has to overcome the impact from the environment and improve their accuracy of field detection.

(3) Developing wireless sensor network technology. Rice, as a widely-planted crop, its sample detection of a single sensor is contingent and the recording work is complicated. The application of wireless sensor network technology can collect data of multiple sensors simultaneously and upload it to the server for real-time online monitoring. The responsiveness, anti-jamming capability and reliability of this technology are especially important.

(4) Combining UAV remote sensing technology. Satellites are susceptible to weather when acquiring remote sensing data, and need to collect data in cloudless weather, and the atmospheric correction of the image will also affect the accuracy and efficiency of data processing. The UAV remote sensing technology is developing day by day, with high resolution and good timeliness, and it is not affected by the weather, but it needs to consider its small observation range and relatively high cost. 
Table 1 Non-point source pollutants in paddy fields water environment and detection methods

\begin{tabular}{|c|c|c|c|c|}
\hline $\begin{array}{l}\text { Type of } \\
\text { pollutant }\end{array}$ & Detection method & Advantages & Disadvantages & $\begin{array}{l}\text { Whether suitable for the } \\
\text { detection of non-point source } \\
\text { pollutants in rice fields }\end{array}$ \\
\hline \multirow{3}{*}{ Total nitrogen } & HTO-CL & $\begin{array}{l}\text { no reagents required, wide linear } \\
\text { detection range }\end{array}$ & $\begin{array}{l}\text { high experimental equipment } \\
\text { requirements }\end{array}$ & \multirow{3}{*}{$\begin{array}{l}\text { suitable for automated } \\
\text { analysis in the laboratory }\end{array}$} \\
\hline & Continuous flow analysis & $\begin{array}{l}\text { automatic continuous analysis for large } \\
\text { batches of samples }\end{array}$ & complex standard use ratio & \\
\hline & $\begin{array}{l}\text { Online Digestion-gas phase } \\
\text { molecular spectroscopy }\end{array}$ & $\begin{array}{l}\text { simple treatment in the early stage, suitable } \\
\text { for high concentration water samples }\end{array}$ & $\begin{array}{l}\text { need high temperature and high pressure } \\
\text { conditions for digestion }\end{array}$ & \\
\hline \multirow{3}{*}{ Total phosphorus } & Ion Chromatography & high recovery rate and good repeatability & $\begin{array}{l}\text { complex processing in the early stage, } \\
\text { high digestion conditions and high } \\
\text { working conditions of the instrument }\end{array}$ & \multirow{3}{*}{$\begin{array}{l}\text { suitable for indoor online } \\
\text { rapid detection, } \\
\text { not for on-site }\end{array}$} \\
\hline & ICP-AES & $\begin{array}{l}\text { accurate and precise, low detection limit } \\
\text { and wide range }\end{array}$ & $\begin{array}{l}\text { experimental water requirements are } \\
\text { strict }\end{array}$ & \\
\hline & Flow injection analysis & $\begin{array}{l}\text { automatic sampling and dilution, online } \\
\text { digestion }\end{array}$ & $\begin{array}{l}\text { inconvenient to directly measure water } \\
\text { samples with high turbidity }\end{array}$ & \\
\hline \multirow{2}{*}{ Nitrate } & $\begin{array}{l}\text { Dual system ion } \\
\text { chromatography }\end{array}$ & $\begin{array}{l}\text { simultaneous analysis of anions and } \\
\text { cations, simple and sensitive, eluent is } \\
\text { automatically generated by water }\end{array}$ & large and expensive instrument & \multirow{2}{*}{$\begin{array}{l}\text { not suitable for on-site } \\
\text { monitoring in paddy fields }\end{array}$} \\
\hline & $\begin{array}{l}\text { Ion selective electrode } \\
\text { method }\end{array}$ & $\begin{array}{l}\text { direct immersion in water for easy } \\
\text { operation }\end{array}$ & $\begin{array}{l}\text { the sample is easily cross-contaminated, } \\
\text { the calibration is cumbersome, and the } \\
\text { potential response curve is unstable }\end{array}$ & \\
\hline \multirow{3}{*}{$\begin{array}{l}\text { Organochlorine } \\
\text { pesticide }\end{array}$} & GC & high selectivity and wide application range & \multirow{3}{*}{$\begin{array}{l}\text { pre-treatment is time-consuming and } \\
\text { labor-intensive, organic reagents are } \\
\text { toxic }\end{array}$} & \multirow{3}{*}{$\begin{array}{l}\text { high requirements, currently } \\
\text { only laboratory testing }\end{array}$} \\
\hline & LC-MS & $\begin{array}{l}\text { suitable for ionic compounds that are not } \\
\text { easily vaporized, have strong polarity, } \\
\text { and have large molecular weight }\end{array}$ & & \\
\hline & GC-MS & $\begin{array}{l}\text { high sensitivity, lower detection limit, } \\
\text { qualitative and quantitative detection }\end{array}$ & & \\
\hline \multirow{5}{*}{$\begin{array}{l}\text { Organophosphorus } \\
\text { pesticide }\end{array}$} & Chromatography & $\begin{array}{l}\text { quantitative analysis, accurate and } \\
\text { sensitive }\end{array}$ & $\begin{array}{l}\text { complex pretreatment, high experimental } \\
\text { equipment and environmental } \\
\text { requirements }\end{array}$ & \multirow{5}{*}{$\begin{array}{l}\text { more used in indoor testing to } \\
\text { solve certain biological } \\
\text { material inactivation } \\
\text { problems can be used for } \\
\text { rapid determination in the } \\
\text { field }\end{array}$} \\
\hline & Immunoassay & convenient, fast, specific and low cost & $\begin{array}{l}\text { radiation protection treatment is difficult, } \\
\text { enzyme is easy to inactivate, and } \\
\text { luminescence system is susceptible }\end{array}$ & \\
\hline & Enzyme inhibition & $\begin{array}{l}\text { fast and easy, suitable for on-site and } \\
\text { large sample testing }\end{array}$ & low sensitivity and low repetition rate & \\
\hline & $\begin{array}{l}\text { Biological or chemical } \\
\text { sensor technology }\end{array}$ & low cost, easy to operate and carry & $\begin{array}{l}\text { vulnerable to the environment, } \\
\text { biomaterials are easily inactivated }\end{array}$ & \\
\hline & Spectroscopy & $\begin{array}{l}\text { high efficiency, simultaneous } \\
\text { determination of multiple elements or } \\
\text { compounds }\end{array}$ & $\begin{array}{l}\text { must have a standard sample that is } \\
\text { identical to the analytical sample } \\
\text { composition and state structure }\end{array}$ & \\
\hline
\end{tabular}

With China's increasing emphasis on the environment and the development slogan of ecological agriculture, it is particularly important to study the non-point source pollution of rice field water environment. Improving the detection efficiency of various pollutants and strengthening the real-time online monitoring technology will provide a theoretical basis for the analysis and restoration of rice field ecosystems in China, and it is of great significance to avoid subsequent large-scale water pollution disasters. This research implements the new concept of innovation, coordination, green, openness and sharing, which is in line with China's ecological civilization construction and sustainable agricultural development strategy.

\section{Acknowledgement}

The authors gratefully acknowledge the financial support provided by the Guangdong Province Key Field R\&D Program(2019B020221001); Guangdong Province Science and Technology Project(2018A050506073); Guangzhou Science and Technology Planning Project(201807010039).

\section{[References]}

[1] Su D B. Study of Non-point source pollution of the representative
Agricultural Basin in Taihu Lake Area. Master's Thesis, He Hai University, Nanjing, China, 18 May 2007.

[2] National Bureau of Statistics of People's Republic of China. 2016 China Statistical Yearbook. China Statistics Press: Beijing, China, 2016.

[3] Lu Y X, Chen Z L, Wang J, et al. Research Progress and Prospects of Surface Water Environment on Non-point Source Pollution. Environmental Protection, 2003, 11, 22-26. doi: 10.14026/ j.cnki.0253-9705.2003.11.007. (in Chinese)

[4] Guan Y T, Su B L, Huang N B, et al. Runoff pollution characteristics of a small paddy plot in Wanting Town of Xiangcheng District, Suzhou City, Jiangsu Province. Journal of Beijing Normal University (Natural Science), 2014, 50, 496-502. (in Chinese)

[5] Xia J, Zhai X Y, Zhang Y Y. Progress in the Research of Water Environmental Nonpoint Source Pollution Models. Progress in Geography, 2012, 31, 941-952. doi: 10.11820/dlkxjz.2012.07.013. (in Chinese)

[6] Chen Q H, Xi Y G, Wang L, et al. Characteristics of nitrogen and phosphorus runoff losses in organic and conventional rice-wheat rotation farmland in Taihu Lake Region. Journal of Agro-Environment Science, 2016, 35, 1550-1558. doi: 10.11654/jaes.2016-0102. (in Chinese)

[7] Wang J, Guo X S, Wang Y Q, et al. Study on dynamics of Nitrogen in different forms in surface water of paddy field under straw return. Journal of Hydraulic Engineering, 2014, 45, 410-418. doi: 10.13243/ j.cnki.slxb.2014.04.005. (in Chinese)

[8] Yang L Z, Feng Y F, Shi W M, et al. Review of the advances and development trends in agricultural non-point source pollution control in China. Chinese Journal of Eco-Agriculture, 2013, 21, 96-101. (in Chinese) 
[9] Zhang W L, Wu S X, Ji H J, et al. Estimation of Agricultural Non-Point Source Pollution in China and the Alleviating StrategiesI. Estimation of Agricultural Non-Point Source Pollution in China in Early 21 Century. Scientia Agricultura Sinica, 2004, 7, 1008-1017. (in Chinese)

[10] Hu Z Y, Guo Z H, Zhou Z M, et al. Application of Chemical Fertilizer and the Loss of Nitrogen and Phosphorus in Paddy Soils in Hunan. Journal of Hunan Agricultural University (Natural Science Edition), 2000, 26, 264-266. doi: 10.13331/j.cnki.jhau.2000.04.008. (in Chinese)

[11] Guo H Y, Wang X R, Zhu J G, et al. Quantitative of Nitrogen from non-point Source pollution in Taihu Lake Catchment. Journal of Agro-environmental Science, 2003, 22, 150-153. doi: 10.3321/ j.issn:1672-2043.2003.02.006. (in Chinese)

[12] Qing X Y, Ren Y F, Lv Z Q, et al. Characteristics of Total Nitrogen and Total Phosphorus Pollution and Eutrophication Assessment of Secondary River in Urban Chongqing. Environmental Science, 2015, 36, 2446-2452. doi: 10.13227/j.hjkx.2015.07.016. (in Chinese)

[13] Ministry of Environmental Protection. Determination of total nitrogen in water by HJ636-2012-Basic potassium persulfate digestion ultraviolet spectrophotometer method. China Environmental Science Press: Beijing, China, 2012

[14] Yang C, Wu R K, Zhu P D, et al. Determination of Total Nitrogen In Water Using High Temperature Oxidation \& Chemiluminescence Method. Chinese Journal of Analytical Chemistry, 2007, 35, 529-531. doi: 10.3321/j.issn:0253-3820.2007.04.013. (in Chinese)

[15] Liu J L, Zhang P, Song B, et al. Comparison study of determination of total phosphorus and total nitrogen in water by continuous flow analysis. Chemical Research and Application, 2016, 28, 936-941. doi: 10.3969/j.issn.1004-1656.2016.07.004. (in Chinese)

[16] Cui K, Zhang H L, Gao M, et al. Determination of total nitrogen in water by online digestion-gas phase molecular absorption spectrometry. Chemical Enterprise Management, 2019, 1, 28. doi: 10.3969/ j.issn.1008-4800.2019.01.017. (in Chinese)

[17] Li Y, Yang H Z. Optimal design of a kind of TN and TP online automatic monitor for water quality. Industrial Water Treatment, 2013, 33, 77-81. doi: 10.11894/1005-829x.2013.33(5).77. (in Chinese)

[18] Wang B, Yang H Z. Development of TN and TP online automatic monitor for water quality. Water \& Wastewater Engineering, 2015, 51, 157-160. doi: 10.13789/j.cnki.wwe1964.2015.0328. (in Chinese)

[19] Han S L, Xiang G H, Tang X Y, et al. A Novel On-Line Total Nitrogen Analyzer Based on Sequential Injection Analysis Technology. Environmental Monitoring in China, 2013, 29, 94-98. doi: 10.19316/j.issn.1002-6002.2013.03.019. (in Chinese)

[20] Wu H L, Hu Z B, Chai X S,et al. Rapid Detection of Ammonia Nitrogen in Water with Dual-Wavelength Spectroscopy. Spectroscopy and Spectral Analysis, 2016, 36, 1396-1399. (in Chinese)

[21] Dong T, Tong J H, Bian C, et al. Experimental study and kinetic analysis of oxidant-free thermal-assistedUV digestion utilizing supported nano-TiO2photocatalyst for detection oftotal phosphorous. Chinese Journal of Chemical Engineering, 2015, 23, 93-99.

[22] State Bureau of Technical Supervision. GB11893-1989 Determination of total phosphorus in water - Ammonium molybdate spectrophotometric method. China Standard Press: Beijing, China, 1989.

[23] Xu S F. Determination of total phosphorus in surface water by ion chromatography. China Measurement \& Test, 2014, 40(06): 49-51.

[24] Yu N. Application Studies to the Determination of Food and Sanitation Inspection by Ion Chromatography. Master's Thesis, Southwest University, Chongqing, China, 5 May 2011. (in Chinese)

[25] Liu L, Gao X Q, Miao Z H, et al. Comparison between Ion-chromatography and Spectrophotometry for Determining Nitrite in Water. China Water \& Wastewater, 2016, 32, 93-96. (in Chinese)

[26] Yang X. Determination of Total Nitrogen and Total Phosphorus in Surface Water by Ion Chromatography. Physical Testing and Chemical Analysis (Part B: Chemical Analysis), 2015, 51, 1619-1620. doi: 10.11973/lhjy-hx201511033. (in Chinese)

[27] Liu J, Liu B B, Han M, et al. Methodology Research for Determination of Total Phosphorus in Water by Inductively Coupled Plasma-Atomic Emission Spectrometry. Spectroscopy and Spectral Analysis, 2018, 38, 1880-1883. (in Chinese)

[28] Li J H. Points Analysis of Flow Injection System in Detecting Total Phosphorus. 《Environmental Engineering》Editorial Board, Industrial Construction Magazine Co., Ltd. 《Environmental Engineering》 Proceedings of the 2018 National Academic Annual Conference (Volume 1), 《Environmental Engineering》Editorial Department, 2018: 4.
[29] Zhu X T, Zhu Z X, Ye M Y. Photocatalytic Degradation of Organic Phosphorus Water in Microreactor and On-line Detection of Total Phosphorus. Chinese Journal of Analytical Chemistry, 2019, 47, 106-111. doi: 10.19756/j.issn.0253-3820.171499. (in Chinese)

[30] Lv H, Li W, Cheng L, et al. Research on the on-line monitoring system for in situ water quality total phosphorus on the basis of micro-control technology. Industrial Water Treatment, 2019, 39, 92-95. doi 10.11894/1005-829x.2019.39(3).092. (in Chinese)

[31] Huang H Q, Hou J J, Weng C, et al. Dynamics of Chlorophyll-a and Its Potential Relationship with Environmental Factors in Typical River of Chongming Island. Ecology and Environmental Sciences, 2016, 25(08): 1369-1375.

[32] Wang J L, Qin Q M, Li J, et al. Water chlorophyll-a retrieval index based on hyperspectral data. Transactions of the Chinese Society of Agricultural Engineering, 2014, 30(03): 128-134.

[33] Zhang S, He B Y. Remote sensing quantitative analysis on red tide of Changjiang estuary water. Journal of Yangtze River Scientific Research Institute, 2004(03): 29-31.

[34] Peppa M, Vasilakos C, Kavroudakis D. Eutrophication Monitoring for Lake Pamvotis, Greece, Using Sentinel-2 Data. ISPRS Int. J. Geo-Inf. 2020, 9, 143.

[35] Lan Y B. deng X L, Zeng G L. Advances in diagnosis of crop diseases, pests and weeds by UAV remote sensing. Smart Agriculture, 2019, 1(02) $1-19$.

[36] Ministry of Environmental Protection. Determination of total nitrogen in water by HJ636-2012-Basic potassium persulfate digestion ultraviolet spectrophotometer method. China Environmental Science Press: Beijing, China, 2012.

[37] Nakagawa K, Amano H, Takao Y, et al. On the use of coprostanol to identify source of nitrate pollution in groundwater. Journal of Hydrology, 2017, 550, 663-668. doi: 10.1016/j.jhydrol.2017.05.038

[38] Shi C L, Zhu J F. Economic evaluation and analysis of chemical fertilizer inputs in Chinese grain production. Journal of Arid Land Resources and Environment, 2016, 30, 57-63. doi: 10.13448/ j.cnki.jalre.2016.283. (in Chinese)

[39] Xu Y Q, Qin H L, Quan Z, et al. Effects of long-term vegetable cultivation on the NO3--N contents in soil profile and groundwater. Research of Agricultural Modernization, 2015, 36, 1080-1085. doi: 10.13872/j.1000-0275.2015.0085. (in Chinese)

[40] Zhang J, Liu Y D, Zhou A G, et al. Spectral Characteristics of Dissolved Organic Matter and Their Implications in Groundwater Contaminated by Nitrate of Lake Concentration Area in Northern Ordos Basin. Geological Science and Technology Information. (accepted)

[41] Sun D M, Zhang X S, Xu P F. Research on Determination Methods of Nitrate in Environmental Water. Leather Science and Engineering, 2009, 19, 36-38. doi: 10.3969/j.issn.1004-7964.2009.05.008. (in Chinese)

[42] Liao D F. Advances in research on toxicological effects and detection techniques of nitrate and nitrite. Biology Teaching, 2013, 38, 4-6.

[43] Zhang H, Song W H, Zhao T. Determination of ammonia nitrogen, nitrate and nitrite in rivers by dual system ion chromatography. Environmental Pollution \& Control, 2013, 35, 75-77+81. doi: 10.3969/j.issn.1001-3865.2013.09.016. (in Chinese)

[44] Liu B Z, Wang L F, Wang Q T, et al. Ion Selective Electrodes for On-line Monitoring of Ammonia and Nitrate in Wastewater. China Water \& Wastewater, 2009, 25, 106-108. doi: 10.3321/ j.issn:1000-4602.2009.10.029. (in Chinese)

[45] Marco R D, Clarke G, Pejcic B. Ion-Selective electrodepotentiometry in environmental analysis. Electroanalysis, 2007, 19, 1987-2001. doi: 10.1002/elan.200703916.

[46] Zhang M, Ang S Simon, Nguyen V C, et al. Rapid nitrate detection system based on ion selective electrode. Transactions of the Chinese Society of Agricultural Engineering, 2009, 25, 235-239. (in Chinese)

[47] He H, Zhou H D, Gao B, et al. Determination of Nitrate and Nitrite in Water Samples Using Gallery Automatic Discrete Analyzer. Spectroscopy and Spectral Analysis, 2013, 33, 434-437. doi: 10.3964/ j.issn.1000-0593(2013)02-0434-04. (in Chinese)

[48] Shuai H D, Ai H T. Study on rapid detection of Nitrate and Nitrite Nitrogen in Water. Shanxi Youth Daily, 2017-11-11(012).

[49] Yu R, Wang Y H, Wang Y Q, et al. Design of Electromagnetic Sensor Used for the Real-Time Detections of Nitrate Concentrations in Water. Journal of Sensing Technology, 2013, 26, 774-778. doi: 10.3969/j.issn.1004-1699.2013.06.004. (in Chinese)

[50] Rahmati O, Melesse A M. Application of Dempster-Shafer theory, 
spatial analysis and remote sensing for groundwater potentiality and nitrate pollution analysis in the semi-arid region of Khuzestan, Iran. Science of the Total Environment, 2016, 568(oct.15): 1110-1123

[51] Yongyoot W, Kumar T N, Taravudh T, et al. Estimation of the Effect of Soil Texture on Nitrate-Nitrogen Content in Groundwater Using Optical Remote Sensing. International Journal of Environmental Research \& Public Health, 2011, 8(8): 3416-3436.

[52] Preetha P P, Al-Hamdan A Z. Integrating finite-element-model and remote-sensing data into SWAT to estimate transit times of nitrate in groundwater. Hydrogeology Journal, 2020: 1-19.

[53] Agathos F, Paschalis D. Environmental assessment of groundwater nitrate pollution using GIS and Remote Sensing, 2008

[54] Dai G H, Liu X H. Affected Sediment-Study on The Migration Behavior of Persistent Organic Pollutants at Water Interface. Environmental Chemistry, 2011, 30, 224-230. (in Chinese)

[55] Lu X X, Zhang S, Chen C Q, et al. Concentration Characteristics andEcological Risk of Persistent Organic Pollutants in the Surface Sediments of Tianjin Coastal Area. Environmental Science, 2012, 33, 3426-3433. doi: 10.13227/j.hjkx.2012.10.033. (in Chinese)

[56] Lao Q B, Jiao L P, Chen F J, et al. Review on Researches of Legacy POPs and Emerging POPs in the Arctic Regions. Progress in Earth Science, 2017, 32, 128-138. (in Chinese)

[57] Ministry of Environmental Protection, Ministry of Foreign Affairs. development and Reform Commission, etc. The amendments to Annex A, Annex B and Annex C and the new amendments to Annex II for the addition of nine persistent organic pollutants to the Stockholm Convention on Persistent Organic Pollutants Notice of Effectiveness. Ministry of Environmental Protection, Ministry of Foreign Affairs. development and Reform Commission, etc.: Beijing, China, 2014

[58] Yang W R, Wang R S, Li F. Organochlorine pesticides distribution and ecological risk assessment in a abandoned industrial site. Acta EcologicaSinica, 2008, 28, 5454-5460. doi: 10.3321/ j.issn:1000-0933.2008.11.029. (in Chinese)

[59] Jin X. dai L S, Chen Q F, et al. Contamination of Organochlorine Pesticides in Great Knots (Calidris tenuirostris) and Red Knots (C.canutus) Journal of Zoology, 2017, 1, 1-10. doi: 10.13859/j.cjz.201701001. (in Chinese)

[60] Kang Y H, Liu P B, Wang Z J, et al. Persistent Organochlorinated Pesticides in Water from Guanting Reservoir and Yongdinghe River, Beijing. LakeScience, 2003, 15, 125-132. doi: 10.18307/2003.0205. (in Chinese)

[61] Shao Y, Yang G S, Liu W H, et al. The study of organochlorine pesticides and polychlorinated biphenyls in surface water around Beijing. Environmental Science in China, 2016, 36, 2606-2613. doi: 10.3969/j.issn.1000-6923.2016.09.009. (in Chinese)

[62] Chen Y. Studies on HCH and DDT Pesticide Residues in Cultivated Soils in Hunan Province. ChinaEnvironmental Monitoring, 2012, 28, 44-47. doi: 10.19316/j.issn.1002-6002.2012.05.010. (in Chinese)

[63] Ding Y, Huang H F, Li H, et al. Residues of Organochlorine Pesticides (OCPs) in Water and Sediments from Nansha Mangrove Wetland. Environmental Science, 2017, 4, 1-13. doi: 10.13227/j.hjkx.201609019. (in Chinese)

[64] Chang M, Wang C C, Zhang J Z, et al. Determination of 19 Kinds of organochlorine pesticides in water by gas chromatography. Environmental Chemistry, 2018, 37, 1165-1168. (in Chinese)

[65] Taghani A, Goudarzi N, Bagherian G. Application of multiwalled carbon nanotubes for the preconcentration and determination oforganochlorine pesticides in water samples by gas chromatography with mass spectrometry. J Sep Sci, 2016, 39, 4219-4226. doi: 10.1002/ jssc. 201600555 .

[66] Wang S S, Li G, Gao L N, et al. GC-MS / MS determination of 12 organochlorine pesticides in water with separation by liquid-liquidextraction. Physical Testing and Chemical Analysis (Part B: Chemical Analysis), 2016, 52, 384-387. (in Chinese)

[67] Shao Y, Yang G S, Han S, et al. Determination of organochlorine pesticides and polychlorinated biphenyls in surface water usingaccelerate solvent extraction coupling with gas chromatography-mass spectrometry. Chinese Journal of Analytical Chemistry, 2016, 44, 698-706. doi: 10.11895/j.issn.0253-3820.150805. (in Chinese)

[68] Qin D L, Gao L, Huang X L, et al. Simultaneous determination of organochlorine pesticides and herbicides residues in water andsediment by gas chromatography tandem mass spectrometry. Environmental Chemistry, 2017, 36, 2366-2374. doi: 10.7524/j.issn.0254-
6108.2017040601. (in Chinese)

[69] Yang M Y, Mao W, Bei W B, et al. Surface Acoustic Wave Immunosensor for Detection of DDT. Journal of Sensing Technology, 2007, 20, 1-4. doi: 10.3969/j.issn.1004-1699.2007.01.001. (in Chinese)

[70] Zhou D K. The method of Zno sensor and chromatographic separation and detection of POPs.Master's Thesis, University of science and technology of China, Hefei, China, May 2016. (in Chinese)

[71] Jiang Y T, Chen W. Research Progress of Determination of Polychlorinated Biphenyls in Environmental Samples by Electrochemical Sensors. Journal of AnalyticalTesting, 2017, 36(10), 1279-1286. doi: 10.3969/j.issn.1004-4957.2017.10.020. (in Chinese)

[72] El-Alfy M A, Hasballah A F, Abd E H T, et al. Toxicity assessment of heavy metals and organochlorine pesticides in freshwater and marine environments, Rosetta area, Egypt using multiple approaches. Sustainable Environment Research, 2019, 29(1).

[73] Liu X Y, Tang J J, Zhang Y, et al. Ecological Risk Assessment of Organophosphorus Pesticides in Water Source Areas of Guangdong, Guangxi and Hainan Provinces. Environmental Science Research, 2015, 28, 1130-1137. doi: 10.13198/j.issn.1001-6929.2015.07.16. (in Chinese)

[74] Ding H D, Wan H Y, Qin P, et al. Occurrence, sources and risk assessment of organophosphorus pesticides in the environment,China Environmental Chemistry. 2019, 38, 463-479. doi: 10.7524/ j.issn.0254-6108.2018051405. (in Chinese)

[75] Guo Q, Tian H, Mao X X, et al. Ecological Risk Assessment of Organophosphorus Pesticides in Aquatic Ecosystems of Pearl River Estuary. Environmental Science, 2014, 35,1029-1034. doi: 10.13227/j.hjkx.2014.03.030. (in Chinese)

[76] Costa L G. Organophosphorus Compounds at 80: Some Old and New Issues. Toxicol Sci, 2018, 162, 24-35. doi: 10.1093/toxsci/kfx266.

[77] Huang $\mathrm{T} T$, Tang $\mathrm{Y}$. dong $\mathrm{X}$ Q, et al. Determination of 23 Organophosphorus Pesticide Residues in Tea by QuEChERS Extraction with Multi-Walled Carbon Nanotubes (MWCNTs) Coupled to Gas Chromatography. Food Science, 2018, 39, 315-321. (in Chinese)

[78] Zhu B Q, Jin S Q, Xu X Y, et al. Determination of 39 Organophosphorus Pesticides in Tea by Online Gel Permeation Chromatography-Gas Chromatography Tandem Mass Spectrometry Coupled with Modified QuEChERS Method. Physical Testing and Chemical Analysis (Part B: Chemical Analysis), 2018, 54, 433-442. doi: 10.11973/ lhjy-hx201804013. (in Chinese)

[79] Wei T L. The Research of Simultaneous Determination of Seven Kinds of Organicphosphorus Pesticide Residues in Drinking Water by High Performance Liquid Chromatography. Master's Thesis, Northwest Normal University, Lanzhou, China, May 2013. (in Chinese)

[80] Lin D P. Residue analysis of 56 pesticides in the soil and water environment. Master's Thesis, Shandong University, Jinan, China, 3 December 2014. (in Chinese)

[81] Wang Q, Song X, Wang L. Research Progress of Detection of Residual Amounts of Organophosphorus Pesticides in Water and Food. Physical Testing and Chemical Analysis (Part B: Chemical Analysis), 2018, 54, 739-744. doi: 10.11973/lhjy-hx201806025. (in Chinese)

[82] Liang D Q, Su K M, Zhang J M, et al. Determination of 23 Organophosphorus Pesticide Residues in Lentinus edodes by High Perform ance Liquid Chrom atography-Tandem M ass Spectrom etry. Food Science, 2014, 35(4), 159-162. doi: 10.7506/ spkx1002-6630-201404033. (in Chinese)

[83] Yin X G, Yin L M, Xu C L. Research Development of Residue Determination of Organophosphorus Pesticides Basedon Multianalyte Immunoassay. Food Science, 2008, 29, 684-688, doi: 10.3321/ j.issn:1002-6630.2008.10.163. (in Chinese)

[84] Fang Q K. Study of Immunoassay for Residue of Pestisides Butocarboxim and Imidacloprid. Master's Thesis, Nanjing Agricultural University, Nanjing, China, June 2015. (in Chinese)

[85] Chen G. Study of Chemiluminescence Immunoassay for the Detection of Parathion. Master's Thesis, Chinese Academy of Agricultural Sciences, Beijing, China, May 2017. (in Chinese)

[86] Zhang P, Gao M C, Zhou Q, et al. Application of biosensors in the detection of organophosphorus pesticides. Chinese Journal of Analysis Laboratory, 2019, 38, 622-626. doi: 10.13595/ j.cnki.issn1000-0720.2018.072306.(in Chinese)

[87] Liu Q, Jiang X R, Zhang Y X. A novel test strip for organophosphorus detection. Sensor Actuat B-Chem, 2015, 210, 803-810. doi: 10.1016/j.snb.2014.12.048.

[88] Dai Y, Wang J H, Han P, et al. Recent progress of biosensors for 
detection of organophosphorus pesticide residues. Journal of Food Safety \& Quality, 2015, 6, 2976-2980. (in Chinese)

[89] Wei M, Wang J J. A novel acetylcholinesterase biosensor based on ionicliquids-AuNPs-porous carbon composite matrix for detection of organophosphate pesticides. Sensor Actuat B-Chem, 2015, 211, 290-296. doi: 10.1016/j.snb.2015.01.112.

[90] Yu G X, Wu W X, Zhao Q, et al. Efficient Immobilization of Acetylcholinesterase Onto Amino Functionalized Carbon Nanotubes for the Fabrication of High Sensitive Organophosphorus Pesticides Biosensors. Biosens Bioelectron, 2015, 68, 288-294. doi: 10.1016/ j.bios.2015.01.005.

[91] Zheng Y Y, Liu Z M, Jing Y F, et al. An acetylcholinesterase biosensor based on ionic liquid functionalized graphene-gelatin-modified electrode for sensitive detection of pesticides. Sensor Actuat B-Chem, 2015, 210, 389-397. doi: 10.1016/j.snb.2015.01.003.

[92] Zhao $\mathrm{H} \mathrm{Y}$, Ji X P, Wang B B, et al. An ultra-sensitive acetylcholinesterase biosensor based on reduced grapheme oxide-Au nanoparticles- $\beta$-cyclodextrin/Prussian blue-chitosan nanocomposites for organophosphorus pesticides detection. Biosens Bioelectron, 2015, 65,23-30. doi: 10.1016/j.bios.2014.10.007.

[93] Mishra R K, Alonso G A, Istamboulie G, et al. Automated flow based biosensor for quantification of binary organophosphates mixture in milk using artificial neural network. Sensor Actuat B-Chem, 2015, 208, 228-237. doi: 10.1016/j.snb.2014.11.011.

[94] Crew A, Lonsdale D, Byrd N, et al. A screen-printed, amperometric biosensor array incorporated into a novel automated system for the simultaneous determination of organophosphate pesticides. Biosensors\&bioelectronics, 2011， 26， 2847-2851. doi: 10.1016/ j.bios.2010.11.018.

[95] Silletti S, Rodio G, Pezzotti G, et al. An optical biosensor based on a multiarray of enzymes for monitoring a large set of chemical classes in milk. Sensor Actuat B-Chem, 2015, 215, 607-617. doi: 10.1016/ j.snb.2015.03.092.

[96] Zhang Y Y, Arugula M A, Wales M, et al. A novel layer-by-layer assembled multi-enzyme/CNT biosensor for discriminative detection between organophosphorus and non-organophosphrus pesticides. Biosens Bioelectron, 2015, 67, 287-295. doi: 10.1016/j.bios.2014.08.036.

[97] Kim B S, Kim G W, He N S, et al. Development of a Portable Biosensor
System for Pesticide Detection on a Metal Chip Surface Integrated with Wireless Communication. Food science and biotechnology, 2015, 24(2) 743-750. doi: 10.1007/s10068-015-0096-x.

[98] Yan X, Li H X, Wang X Y, et al. A novel fluorescence probing strategy for the determination of parathion-methyl. Talanta, 2015, 31, 88-94. doi: 10.1016/j.talanta.2014.07.032.

[99] Liu G Z, Guo W Q, Song D D. A multianalyte electrochemical immunosensor based on patterned carbon nanotubes modified substrates for detection of pesticides. Biosens Bioelectron, 2014, 52, 360-366. doi: 10.1016/j.bios.2013.09.009.

[100] Li F Q, Pan H C, Yuan Y L. Research progresses of DNA aptosensors for pesticide detection. Analysis laboratory, 2018, 37, 488-496. doi: 10.13595/j.cnki.issn1000-0720.2018.0092. (in Chinese)

[101] Li Q, Wang C G, Tian H Q. Application and Prospect of Spectroscopy Technology in Pesticide Residue Test. Research on Agricultural Mechanization, 2014, 36(8), 250-252. doi: 10.3969/ j.issn.1003-188X.2014.08.061. (in Chinese)

[102] Liu C L, Sui S X, Wu J Z, et al. Experimentation of Detecting the Chlorpyrifos Content in Solution by Near Infrared Spectroscopy. Transactions of the Chinese Society for Agricultural Machinery, 2009, 40, 129-131. (in Chinese)

[103] Cao B H, Zhang G X, Zhou Z K. Terahertz Time-Domain Spectroscopy of Dimethoate.In analytical chemistry. 2008, 36, 623-626. doi: 10.3321/j.issn:0253-3820.2008.05.012. (in Chinese)

[104] Yan Z G, Zheng S, Xie Q J, et al. Terahertz Spectroscopic Investigation of Organophosphorus Pesticide Parathion-Methyl. Spectroscopy and Spectral Analysis, 2009, 29, 2622-2625. doi: 10.3964/ j.issn.1000-0593(2009)10-2622-04. (in Chinese)

[105] Chen C, Chen G Q, Li R, et al. The Study of Spectral Characteristics of Several Organophosphate Pesticides. Spectroscopy and Spectral Analysis, 2012, 32(6), 1594-1595. doi: 10.3964/ j.issn.1000-0593(2012)06-1592-04. (in Chinese)

[106] Ma R J, Zhang Y L, Chen Y, et al. Experimental Study on Detection of Chlorpyrifos Concentration in Water by Hyperspectral. Spectroscopy and Spectral Analysis, 2019, 39(03), 923-930. (in Chinese)

[107] Xing Y, Yu X H, Xu Qiang, et al. Research Progress on Determination of Organic Pesticides by Fluorescent Probes. Fine Chemicals. doi: 10.13550/j.jxhg.20190149. (accepted) 